\title{
O AQÜÍFERO GUARANI E SEUS PARÂMETROS JURÍDICOS: PERSPECTIVAS E LÓGICAS DA
} ESCASSEZ DE ÁGUA DOCE

\author{
Christian Guy Caubet
}

Resumo: O Aqüífero Guarani não é um tanque de água subterrâneo. É um conjunto fraturado de eventuais oportunidades de obter água potável em diversos lugares. Quando usadas suas águas, cria-se espaço para receber águas superficiais eventualmente contaminadas. O balanço atual do uso das águas de superfície e subterrâneas, no mundo todo, evidencia que a mercantilização substitui rapidamente as antigas obrigações de políticas públicas de providenciar água de qualidade em quantidades suficientes para o conjunto da população. As normas nacionais e internacionais recém adotadas não são suficientes para reverter 0 quadro atual.

Palavras-chave: Aqüífero Guarani, práticas e normas internacionais para Aqüíferos, normas internas brasileiras para águas de superfície e aqüíferos.

\section{THE GUARANI AQUI FER AND THEIR LEGAL PARAMETERS: PROSPECTS AND LOGIC OF FRESH WATER SCARCITY}

\begin{abstract}
Guarani Aquifer is not a groundwater tank. It is a disrupted chain of eventual opportunities of getting freshwater in many places. Once its water has been used, there is a possibility for surface waters to occupy the place and contaminate it, or facilitate contamination by acting as a vector of percolation. An International Clean Water Act is not sufficient by itself, if it lacks prevention and implementation, and therefore control of public policies. Common actions in the boarder areas could be of more effect than treaty signature without practice goals and common concern. A good ground and starting point for international cooperation could be the common identification of the identical national rules in all the States of the same aquifer concern, as well as real political participation and concern of the regional peoples.
\end{abstract}

Key Words: guarani aquifer, international practices and rules for ground water,domestic brazilian rules for surface and ground waters.

\section{I ntrodução}

O objetivo deste trabalho é de identificar implicações políticas e sociais de opções jurídicas relativas ao aproveitamento humano da água subterrânea potável. Essas opções jurídicas costumam ser apresentadas como naturais e irreversíveis, definidas ao cabo de processos de decisão formalmente inquestionáveis: as autoridades que decidem sobre os problemas cruciais da água são tecnicamente competentes, juridicamente competentes e politicamente legítimas. Elas defendem os interesses de toda a Sociedade. Portanto, não há espaço para dúvida de tipo algum. As leis relativas aos recursos hídricos são os melhores textos possíveis, adotados por Representantes legítimos para resolver problemas objetivos e por todos percebidos de maneira semelhante. Esses problemas são, principalmente, a escassez de água potável, o aumento das necessidades de 
consumo, os investimentos financeiros privados necessários, a imparcialidade "do Estado" frente ao conjunto dos problemas, a poluição crescente das águas de superfície. Esses são elementos suficientemente públicos e notórios para dispensar críticas ou denuncismos irresponsáveis: as autoridades sabem muito bem dos problemas e deles se encarregam. Resumindo: quem lida com problemas de água sabe o que faz e dispensa as criticas de quem não pode decidir.

A ênfase da análise realizada neste ensaio está posta nas relações políticas: considera o Direito como uma das expressões mais aperfeiçoadas do fenômeno político e como a cristalização de relações de mando, em relação à substância água. O estudo tratará de mostrar o quanto os textos jurídicos já transformaram, a partir da Conferência de Mar del Plata, de 1977, o status dos recursos hídricos: passou-se de substância mineral abundante, de qualidade e gratuita, a mercadoria de alto valor econômico. O fato de dedicar a atenção às águas subterrâneas permite perceber como a concentração dos poderes políticos e econômicos se acentuou em relação à água, e como as águas subterrâneas estão desamparadas por este motivo, apesar de estatutos jurídicos novos e eventualmente abrangentes.

Dos pontos de vista acadêmicocientífico e sociais, a expressão Aqüífero Guarani comporta diversas acepções. Dela, pode-se dizer que está em trânsito entre os conhecimentos científicos iniciais (o Sistema Aqüífero Guarani -SAG-) já corrigidos pelo cotejo de dados entre cientistas, e a crença ou desinformação generalizada relativa a sua natureza, funções, capacidades e estatutos jurídicos, do ponto de vista dos direitos internos dos países que dividem as regiões suprajacentes ao aqüífero e também do ponto de vista do Direito Internacional Público. Serão apresentados enfoques jurídicos e políticos de direito e de relações internacionais relativos ao período 19802011. Deste período, herdamos mudanças drásticas, cujas conseqüências mal começamos a delinear. Em relação ao tema em pauta, a escassez relativa de água de qualidade ensejou, de um ponto de vista antropocêntrico, um fenômeno de mercantilização: a substância água, usada desde sempre e universalmente ao bel prazer de necessidades imediatas, passa a ser de acesso restrito: dependendo do uso e do consumidor, a água pode ser gratuita, controlada, vendida ou ....inacessível mesmo para quem queira pagar por ela.

O texto é dividido em três partes, que passam do enfoque "águas de aqüífero" a referências sobre águas doces de superfície. Para ter referências mínimas e entender a gravidade do assunto, é necessário evocar questões de águas superficiais; é a partir das maneiras de organizar o uso destas que se pode entender melhor a problemática dos recursos hídricos subterrâneos. I: os problemas de água potável na sua percepção corriqueira e o recurso óbvio às águas do Aqüífero Guarani; II: o esboço dos parâmetros jurídicos, Declarações e noções de Direito Internacional relativos à água potável; III: polêmicas em torno do direito à água. Neste caso, a temática sai do quadro estreito dos aqüíferos e se inclui em temática mais abrangente: a da água potável e seu estatuto jurídico até a Resolução da ONU sobre a aprovação do acesso à água como direito humano (28/7/2010).

$$
\text { I. } 0 \text { contexto dos }
$$
problemas relativos aos aqüíferos e à 
água em geral, na bolha global dos recursos hídricos.

Em linguagem corrente, a palavra bolha designa um fenômeno de inchaço e eventual explosão, relativo a relações financeiras e contábeis que "fugiram do controle". Por analogia, a noção de bolha, aplicada aos problemas de recursos hídricos, enfatiza situações criticas e desafios não correspondidos por respostas adequadas. No caso, a expressão respostas adequadas significaria, no mínimo, colocar à disposição dos consumidores de água as quantidades de água necessárias, com qualidade também adequada. Os aqüíferos são a atual referência: em um contexto de escassez, eles recebem destaque como solução, apesar de não serem uma solução estrutural adequada. Uma solução estrutural adequada apelaria para a despoluição e a luta contra as contaminações das águas de superfície. Esta solução, atualmente, só enseja medidas paliativas e portanto inoperantes em termos de garantia de eficiência global. Neste contexto, recorrer às águas subterrâneas é ignorar os desafios reais.

I.1. Para que serve um Aqüífero Guarani?

É provável que já exista um imaginário coletivo relativo aos aqüíferos; e que ele tenha desvirtuado os fenômenos que ele procura idealizar. Quando se usa a palavra aqüífero ou a expressão Aqüífero Guarani (CAUBET 2006, p.51-58), é num contexto de escassez de água doce e de seu aproveitamento para o abastecimento das populações humanas. A simples menção dos possíveis usos das águas dos aqüíferos para necessidade usuais deveria levar a desconfiar do fato de que os desafios são consideráveis: por que evocar a necessidade de recorrer sistematicamente a águas subterrâneas, em um pais cuja superfície dispõe da segunda maior abundância hídrica do planeta?

A água dos aqüíferos seria uma panacéia face à escassez cada vez mais certa em relação às águas superficiais. Como o abastecimento de água está se tornando um desafio de difícil solução, por causa da carência de recursos de qualidade na superfície, a resposta salta aos olhos: é só pegar a água boa onde está: no subsolo. Esta atitude, corriqueira na apresentação dos problemas de escassez de recursos hídricos, traz diversos pressupostos de políticas públicas, não necessariamente assumidos ou informados ao público, mas com efeitos duvidosos ou nocivos. Com efeito, as políticas públicas pretendem, explicitamente ou não: a) optar por uma alternativa segura, em matéria de abastecimento de água dos seres humanos utilizadores; b) pressupor que a água de superfície não garante, nem voltará a garantir um abastecimento adequado; c) promover a participação dos cidadãos na administração pública dos problemas; d) deixar de decidir, politicamente, que a água de superfície deve ser restabelecida no statu quo ante: com qualidade e em quantidades que existiam no passado, na época "antes" das circunstâncias que levaram a desistir de garantir a qualidade da água de superfície.

Em função dessas opções importantes, ditas políticas públicas também optam por, implicitamente: i) condenar o subsolo a receber os efluentes artificiais e efeitos crescentes da poluição de superfície; ii) renunciar a enfrentar globalmente os problemas de poluição, isto é: muito além da poluição da água.

I.2. Dimensões simbólicas dos aqüíferos. 
Por que o Aqüífero Guarani já irrompeu no imaginário coletivo como uma panacéia? Em primeiro lugar, por ignorância em relação ao que significam seus números abstratos. O termo Aqǘf́rero Guarani é a denominação dada a um reservatório subterrâneo fracionado e não homogêneo de água doce que jaz sob parte dos territórios de: Argentina (228.255 km²); Brasil [( num total de 735,916 $\mathrm{km}^{2}$ ) nos Estados Membros de: Goiás $\left(39.367 \mathrm{~km}^{2}\right)$, Minas Gerais (38.585 km²), Mato Grosso $\left(7.217 \mathrm{~km}^{2}\right)$, Mato Grosso do Sul (189.451 k²), São Paulo (142.959 $\left.\mathrm{km}^{2}\right)$, Paraná (119.525 $\left.\mathrm{km}^{2}\right)$, Santa Catarina $\left(44.132 \mathrm{~km}^{2}\right)$ e Rio Grande do Sul $\left(154.680 \mathrm{~km}^{2}\right)$ ]; Paraguai $(87.536$ $\mathrm{km}^{2}$ ) e Uruguai $\left(36.171 \mathrm{~km}^{2}\right)$. Com uma reserva estimada em trinta mil $\mathrm{km}^{3}$, foi logo (1995) considerado como o maior do mundo, até que o recente (junho 2010) descobrimento do Aqüífero Alter do Chão, sob a superfície do Estado do Pará, com possíveis oitenta mil $\mathrm{km}^{3}$ de reservas, já o relegasse a posição de destaque menor. Em condições naturais normais, apenas parte do estoque de um aqüífero pode ser aproveitada: é necessário respeitar parâmetros de preservação (áreas e vazões de recarga isentas de poluições; não contaminação; pressões). Para o Aqüífero Guarani, o volume aproveitável representaria de $40 \mathrm{~km}^{3}$ a $80 \mathrm{~km}^{3}$ /ano, ou seja: a possibilidade, pelo menos aritmética, de suprir a totalidade do consumo da população brasileira durante alguns séculos; desde que a poluição, que está tornando inaproveitáveis as águas de superfície abusivamente utilizadas pelos seres humanos, não viesse a dar cabo da qualidade das águas subterrâneas como está afetando as superficiais. Esta visão apocalíptica seria fruto do exagero?
Um caso hipotético para a

reflexão: o Aqüífero de Gaza.

Já foi dito: a água do Aqüífero Guarani "parece água que não acaba mais". Tanto assim, que a população de Ribeirão Preto (SP) faz parte dos usuários que nem estão preocupados com a evidente abundância de seu recurso e consomem uma média de 380 I./habitante/dia, contra uma média nacional brasileira de 180 l. O motivo dessa despreocupação: a água do Aqüífero, considerada infinita.

No dia em que a Assembléia Geral da ONU votou a Declaração Universal dos Direitos Humanos, em 1948, ninguém pensou que num outro dia a mesma AG examinaria uma Resolução para aprovar o acesso à água potável como um Direito Humano. Mas esse dia chegou em 28 de julho de 2010; portanto só demorou 22 anos.

Pode-se tentar alertar os usuários com o exemplo do Aqüífero “de Gaza”? O aqüífero "de Gaza" também interessa ao Egito e a Israel, além dos palestinos da Faixa de Gaza. No mês de setembro de 2009, um relatório do Programa das Nações Unidas para o Meio Ambiente -PNUMA-, alertava para a degradação das condições das águas desse aqüífero, em razão das conseqüências da ação militar israelense na Faixa de Gaza no final de 2008 e início de 2009. Segundo o relatório, as autoridades locais, em Gaza, deveriam suspender imediatamente o uso das águas do aqüífero, que sustenta o consumo doméstico e agrícola de um milhão e meio de palestinos, até encontrarem fontes alternativas, pois os prejuízos resultantes das iniciativas militares israelenses serão irreversíveis em breve. Mas sem a participação conjunta das autoridades dos três países citados, não há motivo de pensar 
que o aqüífero de Gaza possa ser efetivamente preservado, mesmo investindo a quantia de 1,5 bilhões de US\$ em usinas de dessalinização de águas do mar, no intuito de retirar a pressão exercida sobre o aqüífero: (STEINER; 2009).

“O Relatório identifica diversos impactos oriundos da escalada da violência nos meses de dezembro de 2008 e janeiro de 2009. Mas além disso ele aponta para o fato de que por exemplo a condição do aquífero que fornece a água ao povo de Gaza está agora sob grave ameaça. Durante milhares de anos ele manteve habitantes nessa área. Em mais alguns poucos anos ele pode deixar de fazê-lo. Enfrentar essa situação, que resulta parcialmente de exploração excessiva mas agora também de intrusão de água salgada do Mediterrâneo, significará que está requerida uma ação urgente para assegurar que o abastecimento futuro de água de Gaza será garantido."

As águas de superfície, notadamente as do Rio Jordão (Síria, Israel, Jordânia), estão desaparecendo em razão de sua exploração excessiva para a irrigação e da poluição por esgotos domésticos. Como formatar um quadro normativo para resolver esses problemas? Situações políticas complexas em razão de conflitos crônicos, combinadas com recursos vitais que parecem exigir negociações e boa fé entre duas ou mais entidades estatais, podem ser objeto de soluções jurídico-políticas?

II. Esboço de referencias jurídicas.

II . 1. Conferencias e Declarações internacionais
Em 14 de março de 1977, por ocasião da segunda sessão plenária da Conferencia das Nações Unidas sobre a água, seu Secretário Geral observa que é "a primeira vez que os problemas complexos postos à humanidade pela valoração dos recursos hídricos [são] abordados em sua totalidade e de uma maneira sistemática e completa em uma reunião mundial"(ONU, 1977, p.103). O resumo do debate geral também lembrou que a conferência sobre a água era "um elo importante entre uma série de conferências estreitamente vinculadas"; de um lado, as que já tinham tratado do meio ambiente (Estocolmo, 1972), da população, dos recursos alimentares e dos estabelecimentos humanos e, de outro lado, aquelas que estavam então previstas e tratariam da desertificação, da ciência e da técnica ao serviço do desenvolvimento, e da cooperação técnica ao serviço do desenvolvimento.

O objeto dessas conferências, que deveriam ser consideradas no contexto dos esforços então envidados, nas décadas de 1980 e 1990, pelo sistema das Nações Unidas, para instituir uma nova ordem econômica internacional, era convencionar medidas destinadas a melhorar as condições de vida de todos os povos, o que requereria inevitavelmente a redistribuição de recursos tanto em âmbito nacional como internacional, e o uso, para este efeito, de mecanismos institucionais e técnicos apropriados (ONU, 1977, p.103).

Todas as (boas) Resoluções possíveis foram adotadas nesta ocasião; inclusive a respeito da partilha da água entre israelenses e palestinos, pois já faltava boa vontade daqueles em relação ao acesso à água para estes. A Conferencia ocorreu a um tempo em que a Nova Ordem Econômica 
Internacional ainda estava na pauta. Mas, trinta e três anos depois, é forçoso concluir que a situação piorou. Até nos assuntos em que se imaginava que o papel principal seria atribuído aos Estados, constata-se que são estes os acusados de omissão para resolver os problemas sociais, econômicos e ambientais essenciais.

E após Mar del Plata, 1977? Houve muitas conferencias internacionais sobre "os problemas da água" e outras tantas Declarações. Podem ser lembradas as de Dublin (Déclaration de Dublin sur l'eau dans la perspective d'un développement durable, Dublin, Irlanda, 26-31 janeiro de 1992), de San Jose da Costa Rica (Conferencia sobre evaluación y estrategias de gestión de recursos hídricos en America Latina y el Caribe, San José, Costa Rica 6 - 11 de mayo de 1996), de Bonn (The International Conference on Freshwater, 2 a 7 dezembro de 2001) ou de Kyoto (16 a 23 de março de 2002).

Todavia, é a de Dublin que deve ser lembrada, pois é ela que fixou os parâmetros da apreensão econômica politicamente corretos dos recursos hídricos, em quatro referencias principais sempre lembradas desde então.

11.2. As conferências internacionais governamentais não são instrumentos de democracia representativa...

O contexto do uso dos recursos hídricos foi internacionalizado, nas duas décadas passadas, com base nas premissas ultraliberais que apareceram em Dublin. $O$ uso da palavra ultraliberal qualifica comportamentos econômicos e políticos que não são apenas liberais, como ocorria no tempo (início do século XIX) em que se preconizava que o Estado só podia cuidar de polícia, justiça e forças armadas: o "resto" era "do mercado". Os anos 1980-2010 testemunham esforços dos arautos do Mercado para rechaçar a presença do "Estado" para aquém do que era no início dos anos 1980 (Reagan + Thatcher); apesar da necessidade de mais "Estado" para enfrentar novos problemas oriundos da atuação descontrolada do "Estado" durante o mesmo período. Ultraliberal, portanto, qualifica aqui o comportamento de quem quer menos Estado dentro de um contexto em que o Estado já tem políticas de "menos Estado".

Na Conferência de Dublin (1992), a adoção de quatro princípios essenciais encaminha as referências básicas do pensamento único que passará a nortear o planeta. A água é afirmada como: a) recurso insubstituível para a vida; b) sua gestão deve associar os usuários, planejadores e tomadores de decisão em todos os níveis [da ação administrativa-política]; 3) o papel das mulheres é essencial na gestão e na preservação do recurso e 4) a água deve ser reconhecida como um bem com valor econômico. É este quarto "princípio" que receberá, desde então, o impacto da totalidade dos esforços envidados pelos governos e empresas, associados para promover a governança dos recursos hídricos.

Dez anos depois das conferências do Rio de Janeiro e de Dublin (1992) percebeuse (em Johanesburgo, 2002) que a questão dos recursos hídricos era emblemática. Com efeito, a sociedade-de-exclusão que caracteriza as relações sociais de hoje já institucionalizou a segregação em relação ao acesso e ao uso dos recursos naturais e chegou a incluir a água nas suas práticas segregacionistas; muito embora pouco se 
evoque esse aspecto das relações de consumo. Aliás, não é que apenas não se evoque esse assunto, como se ele não tivesse importância. O assunto é um verdadeiro tabu das relações sociais.

O Forum Social Mundial, manifestação social alternativa periódica, considerando a premência desses problemas e a criação de importantes estados-maiores mundiais da água, idealizados para promover a mercantilização e privatização do recurso em âmbito mundial, adotou uma Declaração que objetiva fomentar uma ação internacional contra essas medidas de privatização, contrárias à verdadeira gestão racional dos recursos hídricos. Os estadosmaiores mundiais da água são instituições e conglomerados industriais e financeiros como: Suez; Vivendi;Bechtel; Thames Water; World Water Council; Académie de I'Eau; Water Global Partnership; OMC com a Rodada de Doha etc... Na perspectiva do Fórum Social, os fatos de comprar e vender a água passam a ser operações proibidas: a água não pode ser objeto de comércio, por ser um insumo essencial da vida. A única maneira de lidar com o problema é de garantir 40 litros de água potável gratuita por pessoa e entregá-los no lugar de residência dos interessados. Além dessa quantia, pode-se cobrar pela água. Mas ainda seria necessário declarar que esses 40 litros, definidos como quantidade mínima diária pelos peritos da ONU/FAO, deveriam ser anualmente aumentados, para cada pessoa, sob pena de tornar impossível a meta do desenvolvimento sustentável, noção já proclamada como objetivo universal em 1987, pelo Relatório da Comissão Brundtland, intitulado Nosso futuro comum.

Em relação aos recursos hídricos, quer se considere o assunto do ponto de vista nacional ou planetário, o problema e as soluções muito pioraram durante a última década. Mas no II Fórum Mundial da Água, em Amsterdã (Países-Baixos, 2000), já “não havia alternativa". Com efeito, diversos funcionários e experts do Banco Mundial declararam oficialmente, em nome do Banco, que "não havia alternativa", referindo-se à privatização da água, fato histórico absolutamente incontornável, segundo eles (HALL, 2005, 26).

Mas muitos grupos, em várias países, não renunciaram a garantir, para si mesmos, o direito de dispor de água potável gratuita que a prática das companhias monopolizadoras lhes negava. O exemplo boliviano adquiriu notoriedade mundial. Depois de meses de lutas e da morte de sete pessoas fuziladas durante protestos em março de 2001, em La Paz, os camponeses bolivianos retomaram seus direitos confiscados pela Companhia norte americana Bechtel, beneficiada pela política pública do governo boliviano, então no poder, de impedir que a população explorasse a água de seus próprios poços. Outro exemplo: na Argentina, o Governo de Nestor Kirchner acabou rescindindo o contrato da Sociedade Suez em Buenos Aires. A empresa francesa pressionara para aumentar as tarifas cobradas dos usuários em até $100 \%$, mas sem cumprir as obrigações definidas no seu contrato de concessão: ampliar a rede e distribuir água de qualidade (GARCIA, 2008).

Em todos esses embates (1977-2010), nas principais declarações internacionais relativas à importância da água e às soluções para abastecer os seres humanos, jamais o acesso à água foi proclamado com um direito fundamental. Foi necessária uma mobilização política de governos do "terceiro mundo" para que a ONU adotasse uma 
Resolução sobre o assunto, em 28/7/2010.

Contudo, esta Resolução, mesmo proclamando o acesso à água e ao saneamento básico como um direito humano, não proporciona garantia de atendimento, nem tem efeito jurídico obrigatório para os governos signatários. As Resoluções e recomendações internacionais não possuem os efeitos de Tratados: apenas os tratados internacionais podem ter o efeito de obrigar seus signatários ao cumprimento das cláusulas pactuadas.

II.3. Referencias normativas brasileiras e referencias internacionais.

A partir de 1977, com a Lei 9433 Política Nacional de Recursos Hídricos (BRASIL, 2011a), as autoridades brasileiras passaram a enfrentar a questão política das definições normativas: a definição de políticas públicas. Tanto houve adoção de leis federais e de novas leis estaduais, como de normas de Direito Internacional Público: tratado assinado com os Estados territorialmente implicados no Aqüífero Guarani (BRZEZINSKI, 2011). Não havendo como estudar os pormenores desse conjunto normativo aqui, apenas serão citadas referências bibliográficas que permitem apreender as dimensões do assunto. No essencial, os textos normativos citados possuem inúmeras qualidades. Sua pretensão em incluir a participação política no rol de suas características parece, entretanto, desvinculada das realidades e práticas nacionais (CAUBET, 2004, p.103138). A Resolução CONAMA n. 396, de 3 de abril de 2008, que dispõe sobre a classificação e diretrizes ambientais para o enquadramento das águas subterrâneas e dá outras providências (CONAMA, 2008), é um texto da maior abrangência e pertinência possíveis. É de se perguntar quem terá condições de: 1) entender sua complexidade, em se tratando das instancias judiciárias, especialmente de fiscalização (como Ministérios Públicos federal e estaduais) e 2) fazer garantir sua implementação, já na fase preliminar dos estudos obrigatórios de impacto ambiental. O Tratado de 2010 (Acordo sobre o Aqüífero Guarani, assinado em San Juan - Argentinaem 2 de agosto de 2010) objetiva reafirmar a soberania dos países regionalmente interessados, deixando a definição de normas operacionais para o futuro, com referencias à insuficiente Convenção de New York de 1997, assinada pelos quatro signatários porém ratificada por nenhum deles, mas longe das referencias assinaladas pela resolução da AG da ONU n. 63/124, de 15/1/2009, sobre o Direito dos Aqüíferos Transfronteiriços (BRZEZINSKI, 2010, p. 335-340).

Sobre a questão de considerar o acesso à água como direito humano, ainda há a Resolução A/HRC/15/L.14 que o Conselho de Direitos Humanos da ONU aprovou em 24 de setembro de 2010, sobre “direitos humanos e acesso à água potável e ao saneamento". O Conselho

“afirma que o direito humano a
uma água potável segura e ao
saneamento resulta do direito
a um padrão adequado de vida
e é inextricavelmente ligado ao
direito ao maior padrão
alcançável em material de
saúde física e mental, bem
como ao direito à vida e à
dignidade humana."(ONU,
2010)

III . Polêmicas políticas em torno da definição do Direito à água.

III.1. Rumos das opções jurídicas, da gênese jurídico-politicamente correta aos requisitos de implementação eficiente. 
O Direito pode auxiliar na definição de políticas públicas, para cuja implementação ele é um vetor essencial em âmbito interno e internacional. Garantir o acesso à água para a satisfação das necessidades elementares da vida de toda pessoa e das comunidades humanas é uma obrigação para a sociedade no seu conjunto. É a sociedade organizada que possui as condições de assumir coletivamente $\mathrm{o}$ conjunto dos custos relativos à coleta, ao tratamento, à distribuição, à conservação, à estocagem, às utilizações e ao re-aproveitamento da água, bem como de determinar quais são as quantias disponíveis (em caso de racionamento) e a qualidade indispensáveis para os integrantes da comunidade. Porém, a definição do juridicamente correto resulta diretamente das opções do politicamente correto. Essas duas expressões são autoevidentes, para quem as usa: pessoas que presumem que a participação é um comportamento político e social normalmente praticado nas democracias de mercado.

O conjunto dos custos, para colocar a água à disposição dos usuários, inclui externalidades negativas, que não são consideradas pelos preços-de-mercado. Esses custos são sociais e coletivos: para lograr uma definição justa, entre todos os integrantes da coletividade, há sempre um embate político. Embate não é debate: a discussão não chega a ser democrática pelo fato de existir. As condições da discussão são essenciais. Ela pode ser obstruída ou esvaziada pela apresentação de soluções já prontas, de leis não discutidas ou produzidas sem debate democrático. É só tomar os exemplos do preço da água, do pagamento pelos custos de dispor de água de qualidade ou da noção de acesso livre/gratuito à água.
Segundo os defensores do acesso à água como direito humano, os mecanismos de tarifação individual e a progressividade eventual dos preços da água só podem ser determinados para quantidades de água que ultrapassem o mínimo vital indispensável à sadia manutenção das condições de vida. Para efeito da preservação das condições de sobrevivência humana, existem debates intermináveis sobre a quantidade mínima de que deve dispor um ser humano, em média, cada dia. Seria suficiente a quantidade mínima de 50 litros d'água potável gratuita por dia e por pessoa, como indicam estudos fidedignos da Organização das Nações Unidas:

Suficiência. O abastecimento de água para cada pessoa deve ser suficiente e regular para as necessidades individuais diárias. Uma quantidade suficiente de água deveria normalmente chegar a 50 litros, ou ao nível mínimo essencial (cerca de 20 litros). (ONU/ECOSOC, 2002, p.2)

Mas como podem ser fixadas
simultaneamente duas "quantidades
suficientes" tão diferentes como vinte ou
cinqüenta litros?

Também podem ser lembrados os solenes engajamentos da Agenda 21, através da qual houve, em 1992, no Rio de Janeiro, um apelo universal para providenciar água para as populações humanas do mundo inteiro:

"18.58. Todos os Estados, segundo sua capacidade e recursos disponíveis, e por meio da cooperação bilateral ou multilateral, inclusive com as Nações Unidas e outras organizações pertinentes, quando apropriado, podem estabelecer as seguintes metas:

(a) Até o ano 2000, garantir que todos os residentes em zonas urbanas tenham acesso a pelo menos 40 litros per capita por dia de água potável e que $75 \%$ da população 
urbana disponha de serviços de saneamento próprios ou comunitários;

(b) Até o ano 2000, estabelecer e aplicar normas quantitativas e qualitativas para o despejo de efluentes municipais e industriais;

(c) Até o ano 2000 , garantir que $75 \%$ dos resíduos sólidos gerados nas zonas urbanas sejam recolhidos e reciclados ou eliminados de forma ambientalmente segura.

Além do mínimo vital, as tabelas de preço devem ser progressivas e considerar a quantidade utilizada. Os excessos e abusos de consumo ou de outra utilização devem ser devidamente penalizados".

É dentro desses parâmetros que se pode evocar um direito à água. Entretanto, para que esse direito não seja mais um "direito a" sem conteúdo real, ele só pode existir se nascer com as garantias de que os poderes públicos devem assumir suas obrigações de respeito, de proteção e de implementação (ver ONU/ECOSOC; 2002, p.5).

As ONG exigem que o Estado assuma três obrigações precisas:

Obrigação de respeito: os Estados Partes devem deixar de interferir na fruição do direito de beber água. Isso determina que não pode haver práticas ou atividades que limitem o acesso igual à água, que contribuam para sua poluição ou a diminuição dos estoques, inclusive como medida punitiva.

A obrigação de proteção requer do Estado que ele impeça outras Partes de interferir no gozo da água potável. As autoridades devem controlar todas as atividades, públicas ou privadas, que poderiam ter o efeito de denegar o acesso à água, ou de poluir águas por motivo de atividades industriais ou pela sua extração.
A obrigação de implementação obriga o Estado a adotar todas as medidas necessárias para garantir a plena realização do direito de se beneficiar com água potável. O direito à água deve ser objeto da adoção das necessárias normas legais e de planos de ação que objetivem promover o direito, em condições econômicas suportáveis por todas as pessoas.

Essas concepções e exigências relativas à água são diametralmente opostas às da reforma ultraliberal, que serviu de modelo ao conjunto de normas elaboradas, no Brasil, a partir da Lei 9433/97. A mercantilização (fazer da água uma mercadoria ou commodity), a privatização, a desregulamentação e a renormatização, bem como diversas modalidades de deslocalização, são as características da política preconizada sob a égide dos grandes estados-maiores mundiais.

III. 2. Dimensões práticas e práticas jurídicas no assunto "direito à água".

Uma referência essencial foi a iniciativa da criação do Conselho Mundial da Água. O Conseil Mondial de l'Eau é um agrupamento de centenas de instituições, empresas, agentes do setor público ou privado, agências das Nações Unidas, Banco Mundial e ...algumas ONG. Trata-se de um organismo privado a serviço de interesses particulares. Como associação privada com sede em Marselha (França), o grupo integra Véolia/Água- Suez e a Lyonnaise des Eaux, e inclui a Agência da Água Seine-Normandie e o Cercle Français de I'Eau. No conjunto, as reuniões dessa associação privada promovem os encontros necessários entre os representantes da classe política francesa e os empreendedores que vendem os serviços relacionados à água no mundo inteiro; no 
contexto particular que eclodiu com a Rodada de Doha (novembro 2001) e o Acordo Geral sobre o Comércio de serviços - AGCS- último rebento da OMC. ( BORVON, 2009). A VI Reunião do Conseil Mondial de I'Eau será realizada em Marselha (França) em março de 2012.

O intitulado Conselho Mundial da Água é ambíguo, por não revelar que dito Conselho é um produto da iniciativa privada que objetiva a realização de lucro(s) com a privatização das operações relativas aos recursos hídricos: em primeiro lugar captação, tratamento e distribuição; em seguida: saneamento básico. Esse comportamento é corriqueiro desde o início dos anos 1980. Outro organismo cujo título engana é o Observatoire Social International (idealizado, articulado e movimentado pelo Grupo francês Suez), que reúne periodicamente, para sessões de troca de idéias, pessoas ligadas aos grupos empresariais vendedores de serviços de recursos hídricos.

Esses exemplos geograficamente remotos evidenciam que a água é um produto social, seus usos traduzem relações de força que são geralmente ocultadas. A análise detalhada dessas relações mostra que não é através de um abstrato "direito à água" que as populações sequiosas de abastecimento conseguem satisfazer suas necessidades. A água potável é uma conquista social penosa. Sua consecução já é difícil, contrariamente aos estereótipos mais divulgados, nos países europeus que possuem ampla tradição de respeito mínimo aos direitos sociais, duramente conquistados após a revolução industrial. No caso dos países "do terceiro mundo", é a violência que mais aparece como a característica principal da luta pela água.
Dois eventos internacionais ocorridos no ano de 2009 ilustram aspectos da gravidade dos problemas.

III. 3. A crise mundial da água enseja "direito humano à água"; sem garantia...

Em 12 de março de 2009 foi publicado o Terceiro Relatório Mundial da Água pela Organização das Nações Unidas - ONU-. O terceiro relatório não é um documento irresponsável. É uma publicação científica trienal, que parece logo antes da realização trienal do Conselho Mundial da Água. Sob a coordenação da UNESCO, vinte e seis agências da ONU trabalharam na redação do documento, cuja tonalidade maior é de alarme. No preâmbulo, o Diretor Geral da UNESCO adverte: “Apesar do caráter vital da água, o setor padece de falta de interesse político, de uma má governança e de subinvestimento"(ONU, 2009). O Relatório observa que o crescimento demográfico mundial, de 80 milhões de pessoas / ano, aumenta as necessidades de água em 64 bilhões de metros cúbicos anuais. Poucas pessoas, entretanto, ligaram o contexto da crise mundial da água ao das negociações internacionais sobre a redução dos gases de efeito estufa responsáveis pelo aquecimento climático global do planeta; e seus efeitos desastrosos para a manutenção dos estoques de água disponíveis e a recorrência de catástrofes hídricas. Pelos usos abusivos de suas vazões, aumenta o número dos grandes rios que não chegam mais ao mar. É o caso do Rio Colorado (USA/México), do Nilo, do Rio Amarelo, cujos caudais minguantes parecem longínquos. Por que não atentar, então, para a sorte idêntica que espera o Rio São Francisco?

Essas circunstâncias não parecem ter chamado a atenção dos representantes dos países que compareceram ao $\mathrm{V}$ Fórum 
Mundial da Água, em Istambul, de 16 a 22/3/09. O comunicado final oficial nem evoca o conceito (de Direito à água) cuja proclamação era esperada por mais de 25 mil pessoas que foram discutir os assuntos de recursos hídricos, mas que também tentavam pressionar as delegações dos 142 Estados representados. A ausência de reconhecimento de "um direito humano fundamental à água potável e ao saneamento" provocou a mobilização de muitas pessoas, inclusive de certas delegações oficiais, no intuito de arrancar a formulação pública desse direito. Esses esforços foram em vão e a delegação brasileira se destacou pelo seu papel ativo e discreto contra o reconhecimento. Dizer que essa omissão não impede que surjam acordos internacionais favoráveis ao "direito à água", é desconhecer a força de certas inércias nas relações internacionais: já foi observado que uma resolução de organização internacional, uma proclamação política, uma declaração solene que parecem estabelecer um direito, não são sinônimas da existência desse direito. Em todo caso, o Fórum Mundial da Água acabou gerando uma imensa decepção e consolidando as dúvidas em relação à proclamação de um direito fundamental à água. E nem se discutiu, até o momento, da necessidade de preconizar garantias para a realização desse direito que, separado dos elementos de seu contexto, ainda pode iludir. Mas outras situações ajudam a entender que os desafios são muito maiores do que a proclamação, em tese, do direito humano à água. Inclusive porque esta não outorga garantia alguma de que a água será distribuída aos necessitados, apesar das inúmeras declarações e comentários sobre o assunto, e os inúmeros equívocos dos que pensam que basta pronunciar a palavra "direito" para que o direito surja. Depois do Conselho Mundial da Água de Haia (PaísesBaixos), em março de 2000, a Federação Internacional dos Direitos Humanos -FIDHjá comentara o fracasso das expectativas de se obter um direito humano à água.

Com

efeito, no momento final do segundo Forum Mundial da Água, em Haia, a FIDH se preocupa, uma vez mais, com o crescente risco de ver a água tornar-se simples mercadoria e entregar-se à lógica do mercado. Pois a Declaração final, adotada por consenso no final da conferência ministerial, realizada no âmbito desse Fórum, "volta atrás em relação a um dos ganhos mais importantes desses últimos anos, ao deixar de considerar a água como um 'direito fundamental' e ao adotar a noção de simples 'necessidade fundamental'. Essa distinção é de capital importância quando se sabe que a qualificação de 'direito' faz pesar sobre os Estados a obrigação jurídica de proteger, promover e garantir esse direito fundamental"(FIDH, 2009).

Da maneira como está formulada, esta observação revela que seu autor desconhece que: 1) o Fórum Mundial da Água não é um encontro com o objetivo de redigir tratados e que uma entidade privada não pode redigir tratado; 2) a Declaração final do encontro não é um tratado internacional; 3) a inclusão das palavras "direito à água" em uma declaração privada internacional é inócua para criar um direito individual à água. 4) Se fosse um tratado, o texto simplesmente assinado por todos ainda careceria de ratificação pelos seus signatários, no intuito de fazer desse texto um conjunto de obrigações jurídicas de cumprimento exigível, sob pena de os Estados ratificantes se sujeitarem ao questionamento de sua responsabilidade internacional. Mas outro aspecto deveria preocupar ainda mais. 
O texto da Declaração final de 2000 já aparecia como um regresso. O texto de 2009, nove anos depois, parece pior ainda: o direito humano à água continua ignorado pelos representantes dos Estados, em particular os do Brasil e dos Estados Unidos, estes já sob a (então) nova direção do Presidente Barack Obama; cuja delegação reproduziu a "explicação" de que a água como direito humano envolveria um dever de providenciar - abastecimento dos países do terceiro mundo! Enquanto, por outro lado, o Presidente não poderia comprometer a anuência dos Estados membros de sua própria Federação!!

\section{Considerações finais.}

Em 28/7/2010, a Assembléia Geral da ONU aprovou a Resolução 10967, apresentada pela Bolívia, pela qual reconheceu, apos 15 anos de deliberações, "o acesso a uma água de qualidade e a instalações sanitárias como um direito humano", sem afirmar que cabe aos Estados uma responsabilidade prioritária na implementação da Resolução. A Resolução foi adotada por 122 votos a favor e 41 abstenções.

Entre os Estados que se abstiveram de aprová-la, os EUA justificaram sua posição pelo fato do texto da Resolução descrever o acesso à água de maneira diferente do Direito Internacional e pela falta de transparência nas negociações. A representante do Reino-Unido também se absteve e também afirmou que não existe “base suficiente em matéria de Direito Internacional para reconhecer o direito de acesso à água como um direito fundamental". Declarou-se decepcionada pelo fato do "texto prejulgar dos trabalhos do Conselho dos Direitos Humanos".

O representante da Argentina fez questão de sublinhar que o acesso à água e ao saneamento é um assunto de soberania nacional. A da Nova Zelândia explicou sua abstenção pela fato de que sua Delegação "não tivera tempo de examinar as incidências do texto".

Qual será o efeito dessa Resolução, que não tem o efeito jurídico obrigatório de um tratado internacional e que a doutrina jurídica haverá de relativizar em pouco tempo, qualificando-a como soft Law? O Representante do Peru forneceu a explicação juridicamente correta, ao declarar que votou a favor da Resolução "sabendo que a garantia de aplicação desse direito está submetida a uma Diretriz territorial e à votação de um orçamento" pelo seu próprio governo nacional, em âmbito de competência doméstica. Quanto ao representante dos Países-Baixos, pode ter acertado a desculpa politicamente correta (sic), ao ponderar, para justificar sua abstenção: "Esta Resolução não insiste o suficiente na responsabilidade dos Estados para com seus cidadãos. Estes devem poder exigir prestação de contas a seu governo e exigir mecanismos de indenização".

As atitudes individuais e coletivas em relação à água de superfície são essas. Em relação às águas subterrâneas, as normas jurídicas de Direito Internacional Público resultaram de negociações que objetivavam preservar os direitos soberanos dos quatro Estados signatários do Tratado em relação aos Estados exteriores à região. A Resolução do Conselho de Defesa de Direitos Humanos da ONU, confirmando a que fora adotada pela Assembléia Geral em 28/7/2010, provocou declarações circunspectas de diversos 
representantes de Estados, lembrando que não constituem textos jurídicos coercitivos. É lógico pensar que a sede do mundo deverá crescer, pois as garantias de dessedentação estão longe de acompanhar as exigências objetivas das necessidades dos seres vivos.

\section{Referencias Bibliográficas}

ACADÉMIE DE L'EAU. De l'eau pour tous. Um aperçu des travaux menés sur le droit à l'eau potable et la solidarité pour l'eau. Nanterre: Agence de l'Eau Seine Normandie. 2004.

BORVON, Gérard. Análise detalhada do Conseil Mondial de l'Eau in http://www.seaus.free.fr. Acesso em 21/5/09

BRASIL. Lei n. 9433, de 8 de janeiro de 1997. Acesso em 20/6/2011: htttp: //www. presidencia.gov.br/legislacao/

BRASIL. Agência Nacional de Águas - ANAConjuntura dos recursos hídricos no Brasil : informe 2011. Brasília : ANA, 2011. 112 p. : II.

BRASIL. Conselho Nacional do Meio Ambiente - CONAMA-. Resolução CONAMA n. 396, de 3 de abril de 2008. Dispõe sobre a classificação e diretrizes ambientais para o enquadramento das águas subterrâneas e dá outras providências. Publicada no Diário Oficial da União n. 66, de 7 de abril de 2008, Seção 1, páginas 64-68.
BRZEZINSKI, Maria Lúcia Navarro Lins. Direito Internacional em matéria de água doce: conteúdo, formas e efetividade. Brasil. 2011. 382 f. Tese (Doutorado em Direito) Faculdade de Direito, Universidade do Estado do Rio de Janeiro, 2011. 369p.

BRZEZINSKI, Maria Lúcia N. L. Regulating Transboundary Groundwater: big challenges for Brazil In: ISARM 2010 International Conference "Transboundary Aquifers: challenges and new directions". Paris: Unesco, 2010, p. $81-82$.

CAUBET, Christian Guy. A água, a lei, a política... e o meio ambiente? Curitiba: Juruá. 2004. 305 p. Cf.: Capítulo 3: Gestão das águas e cidadania. p. 103-138

-...-. A água doce nas relações internacionais. Bauru (SP): Manole. 2006. $223 p$.

-..-. "Os contextos normativos brasileiros em matéria de águas subterrâneas". In RIBEIRO, Wagner Costa. Governança da água no Brasil. Uma visão interdisciplinar. São Paulo: Annablume. 2009. p. 213-237.

-.-.-.. “Los marcos jurídicos nacionales y supranacionales vigentes en relación al 


\begin{abstract}
Acuífero Guaraní". In Grupo de Trabajo: Iniciativa Mercosur .PIDHDD Capítulo Uruguay. El Acuífero Guaraní en debate. Montevideo (Uruguay): Editorial Cotidiano Mujer, 2009. 116 p (P.67-76) [Enfoques sobre el Acuífero Guaraní. Seminario "Acuífero Guaraní: Sustentabilidad y Desafíos del Derecho al Agua" realizado en Montevideo en noviembre de 2008 en el marco del MERCOSUR.]
\end{abstract}

FIDH - Federação Internacional dos Direitos Humanos. Cf. www.fidh.org: L'accès à l'eau sacrifié sur l'autel du marché. 2 ème Forum Mondial de I' eau. 23 mars 2000. Acesso em $31 / 5 / 09$.

HALL, David. "Introdução". In BALANYÁ, Belén et alii. Por un modelo público de agua. Triunfos, luchas y sueños. Espanha: El Viejo Topo. 2005, p. 26.

GARCÍA, Aniza. El derecho humano al água. Buenos Aires: Editorial Trotta. 2008. 295 p.

ORGANIZAÇÃO DAS NAÇÕES UNIDAS ONU-. Rapport de la Conférence des Nations Unies sur l'eau. Mar del Plata, 14 25 mars 1977. New York: Nations Unies, 1977. E/CONF.70/29, 188 p.)

ONU. Rapport mondial des Nations Unies sur la mise en valeur des ressources en eau. Terceira Edição, 16 de março de 2009.

ONU (a). Assemblée générale. Soixantequatrième session. $108^{\mathrm{e}}$ séance plénière - AG 10967.Droit fondamental à l'eau et à I'assainissement . (A/64/L.63/Rev.1. 28/7/2010)
ONU (b). Conselho de Direitos Humanos. Resolução A/HRC/15/L.14, de 24 de setembro de 2010, pela qual o Conselho:

"Affirms that the human right to safe drinking water and sanitation is derived from the right to an adequate standard of living and inextricably related to the right to the highest attainable standard of physical and mental health, as well as the right to life and human dignity".

STEINER, Achim. UNEP Annual Report 2009.

United Nations Environment Programme (UNEP). UNO: New York. 15/7/2010. 749p.

"The report identifies a number of direct impacts following the escalation of violence in December 2008 and January 2009. But in addition to that it also points to the fact that, for instance the issue of the water aquifer that supplies the water to the people of Gaza is now highly threatened. For thousands of years it has maintained people in that area. In a few more years it may not be able to do so. To address this issue, partly from over extraction but also because of salt water intrusion now coming from the Mediterranean, will mean that urgent action is needed to ensure that the future water supplies of Gaza can be assured."

UNITED NATIONS. Economic and Social Council. Committee on Economic, Social and Cultural Rights. $29^{\text {th }}$ Session. Geneva, 11-29 November 2002. E/C.12/2002/11, p. 2: 